\title{
Covid -19 - A Few Words -- The Way to Come Out
}

Swami Shraddhamayananda

Ramakrishna Mission Charitable Dispensary, Belur Math, Howrah, WestBengal, India

Corresponding author: Swami Shraddhamayananda, Ramakrishna Mission Charitable Dispensary, Belur Math, Howrah, WestBengal, India.

Received date: June 14, 2020; Accepted date: July 06, 2020; published date: July 15, 2020

Citation: Swami Shraddhamayananda. Covid -19 - A Few Words-The Way to Come Out. J Clinical Research and Reports, 4(5); DOI:10.31579/26901919/097

Copyright: () 2020 Vrushali Abhyankar. This is an open access article distributed under the Creative Commons Attribution License, which permits unrestricted use, distribution, and reproduction in any medium, provided the original work is properly cited.

There are some anecdotal remedies from time immemorial in our country. The Vedas and Upanishads have been documented and has inspired Manu and Sushrut in culminating medicine into an evolved concept steeped in belief, common faith and evidence based practices. Some herbs, some vegetables, some condiments and certain spices have been the bane of ayurveda and has helped with digestive disorders, hypertension, insomnia and some memory kinetics - which has also propelled us as a nation into an involvement with homeo medicines. All these with the recent advances of technology and medicine can combat the raging pandemic of COVID 19. The role of food - fruits, vegetables and certain dairy products does have different roles to play in gaining over the virus. With tea it has been a century old belief that it holds a key to the immune response of mankind and the Orient stands by this at all times for many many years since mankind first saw the blue moon.

Uncooked but well washed food has been able to ward off diseases in many pockets of rural communities in the country.

We come across the views of some scientist across the world regarding "COVID - 19" that the virulency of viruses has come down in different country like India. This may not be true. Even inIndia in few state morbidity is very less than few other state. It may be due to common use of herbs spices and tea or coffe wihich may increase the immunity against the disease.

However there are certain proven success with medicines for disrupting the viral swing and paving a formidable recovery process for this dreaded disease which has taken over the world and winning the battle till now. There is no army here, there is no commanding officer here and neither there are rockets or nuclear arsenal in use! But that tiny virus which cannot be seen - can be tackled by homeo medicines - though arbitrary but no harm may come if tried well in time now.

There has been no time for ethics committee or clinical trials or phases of a properly conducted step by step procedure in place. But still my years of experience and dealing with moribund patients who lost their hopes and hearts - could recover with these medicines. My humble effort in restoring the human faith in these times of rising cost of lives, rising number of uncared and undocumented deaths - helped me in accepting this challenge and propagating this meaningful information for common use across regions, nations and the global community at large. But some preventive measures is most essential along with these medicines.

\section{Covid prevention essentially entails:}

1) Distance maintaining of 6 feet or even more
2) Masking (N 95 and surgical masks)

3) Frequent hand washing with soap and water

4) Use alcohol based hand rub (alcohol must be at least 70\%)

5) Thermal screening - at entry points (for unknown person)

6) Avoiding crowded places (restaurants, cinema halls, market places)

7) Immunity producing Herbs, spices, tea etc.

8) Regular exercise, Simple Pranayam, Meditation and prayers.

9) A nutritious and well balanced diet. Avoid fast food.

10) Some homeopathic Medicines may help

a) Rhus Tox 200 as prventive, to be taken weekly one drop

b) Belladonna 6 one drop four times a day as curative for the West

c) Bryonia $200 \&$ Gelsemium 30 may be the curative for India.

\section{Corona has given a great lesson to us.}

1) It literally crushed the Ego of modern science, pride of a nation, of any individual, of a certain society and so on.

2) It has shown the Cosmic power of Nature, where we are helpless against a tiny microbe that made no differences between rich and poor, between superpower and Powerless - the black and the white, the haves and the have nots, the young and the old, the marginalised and the wellheeled, the money spinners and the day dreamers, the able bodied and the disabled

3) So, we pray for the welfare of the society: regular prayer and meditation have been shown in numerous scientific studies that it is to be an important factor in living longer and staying healthy.

\section{Regarding Lock down -}

In India, we have come across in social media that Lock down has no effect. It not at all good to coments regading this critical situation. I shall request them them to read carefully the recent comparison reports of corona infection between Pakistan and a state (UP ) of the neighbouring country where the population is almost same and see the outcome result of New York in USA and Punjub State of India. 